\title{
Effect of Moringa oliefera leaves on blood pressure in hypertensive patients
}

\author{
Kumar Sai Sailesh ${ }^{1}$, Jabir P K ${ }^{2, *}$, Madhusudhan $\mathbf{U}^{3}$, Archana $\mathbf{R}^{4}$, Mukkadan J K ${ }^{5}$

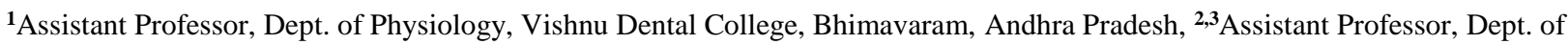 \\ Physiology, DMWIMS Medical College, Wayanad, Kerala, ${ }^{4}$ Professor, Dept. of Physiology, Saveetha Medical College, \\ SIMATS, Thandalam, Chennai, Tamil Nadu, ${ }^{5}$ Research Director, Little Flower Medical Research Centre, Angamaly, \\ Kerala, India \\ *Corresponding Author: \\ Email: jabspk@gmail.com
}

Received: $27^{\text {th }}$ March, 2018

Accepted: $3^{\text {rd }}$ May, 2018

\begin{abstract}
Introduction: Moringa oleifera is the most widely cultivated species of the genus Moringa, which is the only genus in the family Moringaceae. Most nutritious part of the plant is its leaves, and is a good source of vitamin B vitamins and C. It has been reported Moringa oleifera shows antidiabetic effect. The leaf extract contains flavonoids, polyphenols, lycopene, and $\beta$-carotene, and possessed 2, 2-diphenyl-1-picrylhydrazyl, hydrogen peroxide, and hydroxyl radical scavenging activities.

Objective: The present study is designed to conduct effect of Moringa oleifera leaves on blood pressure among human subjects. Materials and Methods: A total of 20 males who are diagnosed with stage -1 hypertension patients with in the age group of 3550 years were selected in the study as cases. The participants served as self-controls. Moringa oleifera leaves juices were prepared and provided to the subjects two times in a day (15 leaves extract one time) for the period of 30 days. Diamond digital sphygmomanometer is used to take the blood pressure.

Results: There was a significant decrease in both systolic and diastolic blood pressure followed by the intervention ( $\mathrm{P}<0.0001 *)$. Conclusion: Thus the Moringa leaf can provide desired effect as a natural control measure for high blood pressure and can be regarded as an alternative medicine.
\end{abstract}

Keywords: Moringa oleifera, Blood pressure.

\section{Introduction}

Moringa oleifera is the most widely cultivated species of the genus Moringa, which is the only genus in the family Moringaceae. English common names include: Moringa, drumstick tree. Most nutritious part of the plant is its leaves, and is a good source of vitamin $\mathrm{B}$ vitamins and $\mathrm{C}$. It also contains provitamin $\mathrm{A}$ as betacarotene, vitamin $\mathrm{K}$, manganese, and protein, among other essential nutrients. ${ }^{1}$ Calcium present in Moringa leaves is bound as crystals of calcium oxalate. ${ }^{2}$ It has been reported Moringa oleifera shows antidiabetic effect. The leaf extract contains flavonoids, polyphenols, lycopene, and B-carotene, and possessed 2, 2-diphenyl-1-picrylhydrazyl, hydrogen peroxide, and hydroxyl radical scavenging activities. A Study on $\mathrm{Db} / \mathrm{db}$ mice with $\mathrm{M}$. oleifera significantly reduced the altered fasting plasma glucose, triglyceride, and lowdensity lipoprotein cholesterol. The same study showed histopathological damage and expression levels of tumor necrosis factor-alpha, interleukin (IL)-1 $\beta$, IL-6, cyclooxygenase- 2 , and inducible nitric oxide synthase in renal tissue decreased. ${ }^{3}$

It has been shown that water extract of leaves of Moringa reduced the chronotropic and inotropic effects on the isolated frog heart. ${ }^{4}$ Bio assay- guided analysis of extract of Moringa oleifera leaves shown hypotensive activity which is attributed to nitrite glycosides like niazirin and niazirinin. ${ }^{5}$ Intravenous administration of either one of these compounds produced reduction in blood pressure and lowering of heart rate in anaesthetized rats. ${ }^{6}$ In another study it was shown that the extracts like thiocarbamate glycosides from Moringa oleifera have hypotensive effects. ${ }^{7}$ Similarly hypotensive effects of Constituents like thiocarbamate and isothiocyanate glycosides from the Pods of Moringa oleifera were also demonstrated. ${ }^{7}$ Most of the studies conducted are on animal models and there are fewer studies conducted on humans. Hence, Present study is designed to conduct effect of Moringa oleifera leaves on blood pressure among human subjects.

\section{Materials and Methods}

Participants: A total of 20 males who are newly diagnosed with stage-1 hypertension and not yet under the medication patients with in the age group of 35-50 years were selected in the study as cases. The participants served as self-controls. The participants with any other systemic illness and those under the medications or following any other therapy and those not willing to provide informed consent were excluded from the study.

Study Setting: The present experimental study was performed at Little Flower Hospital and Research Centre, Angamaly, Kerala. The study was approved by institutional ethical committee. Informed consent was obtained from all the participants.

Intervention: $150 \mathrm{ml}$ of Moringa oleifera leaves juices were prepared and provided to the subjects two times in a day for the period of 30 days. 
Methods: Take Moringa oleifera leaves \& crush them, filter the mixture with the help of a muslin cloth then add a teaspoon of honey in to the juice. This juice was given to the samples twice a day (in the morning before meal \& after meal at night time).

Measurement of Blood Pressure: Quantitative analysis is done by the survey. The readings of persons with high blood pressure are noted down before and after the intervention. Diamond digital sphygmomanometer is used to take the readings. Recording of BP was based on new ACC and American Heart Association (AHA) guidelines.

Data Analysis: Data was analyzed by SPSS 20.0. Student t test was used to observe the significance of difference between pre and post values. Data was presented as Mean and SD. P value less than 0.05 was considered significant.

\section{Results}

The results were presented in table 1 and 2 .

Table 1: Demographic data of the participants

\begin{tabular}{|l|c|}
\hline \multicolumn{1}{|c|}{ Parameter } & Value \\
\hline Age (years) & $42 \pm 8$ \\
\hline Height $(\mathrm{cm})$ & $165.09 \pm 2.46$ \\
\hline Weight $(\mathrm{kg})$ & $122 \pm 10$ \\
\hline
\end{tabular}

Data was presented as mean and SD

Table 2: Blood pressure of the participants before and after Moringa oleifera leaves juices administration

\begin{tabular}{|l|c|c|c|}
\hline \multicolumn{1}{|c|}{ Parameter } & Pre-intervention & Post-intervention & P value \\
\hline Systolic blood pressure $(\mathrm{mmHg})$ & $140 \pm 22$ & $111 \pm 12$ & $0.0001^{*}$ \\
\hline Diastolic Blood Pressure $(\mathrm{mmHg})$ & $97 \pm 15$ & $79 \pm 10$ & $0.0001^{*}$ \\
\hline
\end{tabular}

$* \mathrm{P}<0.01$ is significant. Data was presented as mean and SD

\section{Discussion}

In the present study Moringa oleifera (MO) leaves juice was given to subjects for 30 days. It is clear from Table 1 that subjects are obese. It is well known the relation between obesity and hypertension. It was found that systolic blood pressure is drastically reduced in our present study. The $P$ value is 0.0001 which shows it is statistically very significant. Similarly diastolic blood pressure is very much reduced after administration of the juice. $\mathrm{P}$ value of diastolic blood pressure is also the same as that systolic blood pressure. This shows that both systolic blood pressure and diastolic blood pressure reduced significantly after administration of MO leaves juice.

Moringa oleifera $(M O)$ leaves contain several bioactive compounds, which have been used for stabilizing blood pressure, including nitrile, mustard oil glycosides and thiocarbamate glycosides. ${ }^{9}$ The isolated four pure compounds, niazinin $\mathrm{A}$, niazinin $\mathrm{B}$, niazimicin and niazinin $\mathrm{A}+\mathrm{B}$-from ethanol extract of $M O$ leaves showed a blood pressure lowering effect in rats, mediated possibly through a calcium antagonist effect. $^{10,11}$ A recent study reported that $M O$ reduced vascular oxidation in spontaneously hypertensive rats. ${ }^{12}$

Few studies also shown that Moringa oleifera did not modify blood pressure in hypertensive rats but reduced nocturnal heart rate and improved cardiac diastolic function. Left ventricular anterior wall thickness, interseptal thickness on diastole, and relative wall thickness were reduced after $M O$ treatment. ${ }^{12,13}$

High blood pressure is associated with increased reactive oxygen species (ROS) formation in vessels and target organs such as the brain and kidney. ${ }^{14}$ ROS increase vascular dysfunction by promoting inflammation, thus establishing a positive feedback mechanism that participates to the development of hypertension. ${ }^{15} \mathrm{O}_{2}{ }^{-}$, essentially of NOX origin, reduces endothelial NO bioavailability and promotes nitrosative stress leading to endothelial dysfunction and vascular tone increase that also contributes to hypertension. ${ }^{16,17}$

Oxidative stress is known to be causally involved in the endothelial dysfunction associated with hypertension MO effectively acts as antioxidants and reduce oxidative stress by relaxing resistant arteries in hypertension. ${ }^{18}$

Use of Moringa oleifera seeds in diet against cardiovascular disorders associated with oxidative stress and inflammation such as hypertension has shown to attenuate vascular oxidative and nitrosative stresses. Oral administration of Moringa oleifera seeds demonstrates vascular antioxidant, anti-inflammatory, and endothelial protective effects in hypertension. ${ }^{12}$

The beneficial vascular effects observed in the present work are probably due to the presence of tocopherols, phenolic acids (gallic and ferulic acids), and flavonoids (such as quercetin, catechin, and epicathechin) known for their potential antioxidant activity. ${ }^{19}$

In our study number of subjects was restricted to 20. One of the reasons for this was the difficulty for getting consent from subjects for conducting the study. Another limitation for the study was subjects were kept as self control. Therefore further studies should be conducted in larger population and with control group.

\section{Conclusion}

Moringa oleifera, commonly called as Drumstick plant, is a reservoir of abundant number of phytochemicals which have protective or disease preventive properties. The intake of Moringa leaf, by boiling with water can effect in the regulation of high blood pressure to a normal rate. This is due to the presence of various phytochemicals like, tannins, flavonoids, saponins, anthraquinones, alkaloids and reducing sugars, triterpanoids and steroids. Among this, 
flavanoids being a strong antioxidant have the properties to reduce blood pressure.

As the analysis done by the survey many agreed that it is effective than the modern medicine. The use of Moringa leaf gave a constant change; that too in a short period of time while modern medicine do not give a constant change in blood pressure reading. Thus the Moringa leaf can provide desired effect as a natural control measure for high blood pressure and can be regarded as an alternative medicine. Modern medicine drugs are made in such a way that only the needed phytochemical content is extracted and prepared the medicine. But when we intake the leaf as a whole, many phytochemical contents present in it work together and make the action more effective. Future studies have to carry out on pharmacological studies using extracts to support the use of $\mathrm{M}$. oleifera as a medicinal plant.

\section{References}

1. Leone A, Spada A, Battezzati A, Schiraldi A, Aristil J, Bertoli S (2015). "Cultivation, Genetic,

Ethnopharmacology, Phytochemistry and Pharmacology of Moringa oleifera Leaves: An Overview". Int J Mol Sci. 16 (6):12791-835.

2. Olson, M. E.; Carlquist, S. (2001). "Stem and root anatomical correlations with life form diversity, ecology, and systematics in Moringa (Moringaceae)". Botanical Journal of the Linnean Society. 135(4):315-348.

3. Tang Y, Choi E-J, Han WC, Oh M, Kim J, Hwang J-Y, et al. Moringa oleifera from Cambodia Ameliorates Oxidative Stress, Hyperglycemia, and Kidney Dysfunction in Type 2 Diabetic Mice. J Med Food. 2017 May;20(5):502-10.

4. Dangi SY, Jolly CI, Narayanan S. Antihypertensive Activity of the Total Alkaloids from the Leaves of Moringa oleifera. Pharm Biol. 2002 Jan 1;40(2):144-8.

5. Faizi S, Siddiqui BS, Saleem R, Siddiqui S, Aftab K, Gilani AH. Isolation and Structure Elucidation of New Nitrile and Mustard Oil Glycosides from Moringa oleifera and Their Effect on Blood Pressure. J Nat Prod. 1994 Sep 1;57(9):1256-61.

6. Anwar H. Gilani, Khalid Aftab, Amin Suria, Salimuzzaman Siddiqui, Rubeena Salem, Bina S. Siddiqui, Shaheen Faizi. Pharmacological studies on hypotensive and spasmolytic activities of pure compounds from Moringa oleifera. Phytotherapy Research. 1994 Mar 8:(2):87-91.

7. Faizi S, Siddiqui BS, Saleem R, Siddiqui S, Aftab K, Gilani A-U-H. Fully acetylated carbamate and hypotensive thiocarbamate glycosides from Moringa oleifera. Phytochemistry. 1995 Mar 1;38(4):957-63.
8. Faizi S, Siddiqui BS, Saleem R, Aftab K, Shaheen F, Gilani A-H. Hypotensive Constituents from the Pods of Moringa oleifera. Planta Med. 1998 Apr;64(3):225-8.

9. Vergara-Jimenez M, Almatrafi MM, Fernandez ML. Bioactive Components in Moringa Oleifera Leaves Protect against Chronic Disease. Antioxidants. 2017;6(4):91. doi:10.3390/antiox6040091.

10. Anwar F, Latif S, Ashraf M, Gilani AH Moringa oleifera: a food plant with multiple medicinal uses. Phytother Res. 2007 Jan;21(1):17-25.

11. Dubey D.K., Dora J., Kumar A., Gulsan R.K. A Multipurpose Tree-Moringa oleifera. Int J Pharm Chem Sci. 2013;2:415-423.

12. Randriamboavonjy JI, Rio M, Pacaud P, Loirand G, Tesse A. Moringa oleifera Seeds Attenuate Vascular Oxidative and Nitrosative Stresses in Spontaneously Hypertensive Rats. Oxid Med Cell Longev. https://doi.org/10.1155/2017/4129459

13. Randriamboavonjy JI, Loirand G, Vaillant N, Lauzier B, Derbré S, Michalet S, Pacaud P, Tesse Cardiac Protective Effects of Moringa oleifera Seeds in Spontaneous Hypertensive Rats. A. Am J Hypertens. 2016 Jul; 29(7):873-81.

14. Fukai T, Ushio-Fukai M Superoxide dismutases: role in redox signaling, vascular function, and diseases. Antioxid Redox Signal. 2011 Sep 15;15(6):1583-606.

15. Xu S, Touyz RM Reactive oxygen species and vascular remodelling in hypertension: still alive. Can J Cardiol. 2006 Sep;22(11):947-51.

16. McIntyre M, Bohr DF, Dominiczak AF Endothelial function in hypertension: the role of superoxide anion. Hypertension. 1999 Oct;34(4 Pt 1):539-45.

17. Spieker LE, Noll G, Ruschitzka FT, Maier W, Lüscher TF Working under pressure: the vascular endothelium in arterial hypertension. J Hum Hypertens. 2000 OctNov;14(10-11):617-30.

18. Ballinger S. W., Patterson C., Yan C. N., et al. Hydrogen peroxide-and peroxynitrite-induced mithocondrial DNA damage and dysfunction in vascular endothelial and smooth muscle cells. Circulation Research. 2000;86:960 966. doi: 10.1161/01.RES.86.9.960

19. Leone A, Spada A, Battezzati A, Schiraldi A, Aristil J, Bertoli S Moringa oleifera Seeds and Oil: Characteristics and Uses for Human Health. Int J Mol Sci. 2016 Dec 20;17(12):2141. doi: 10.3390/ijms 17122141

How to cite this article: Kumar SS, Jabir PK, Madhusudhan U, Archana R, Mukkadan JK. Effect of Moringa oliefera leaves on blood pressure in hypertensive patients. Ind $\mathrm{J}$ Clin Anat Physiol. 2018;5(3):350-352. 